\title{
Pure Hydrolyzable Cellulose from Rice Straw, Wheat Straw and Sugarcane Bagasse by a Simple Scalable Two-Step Treatment
}

\author{
Asodekar Bhupal Ravindra ${ }^{1}$, Wadekar Prathamesh Chandrashekhar ${ }^{1}$, Patil Parmeshwar Shivajirao ${ }^{1}$, \\ Patil Mallikarjun Laxmiputra ${ }^{1}$, Lali Mallinath Arvind ${ }^{2 *}$
}

${ }^{1}$ DBT-ICT Centre for Energy Biosciences, Institute of Chemical Technology, Nathalal Parikh Marg, Matunga, Mumbai, Maharashtra, India ${ }^{2}$ Institute of Chemical Technology, Nathalal Parikh Marg, Matunga, Mumbai, Maharashtra, India

E-mail: arvindmlali@gmail.com

Received: 8 September 2020; Revised: 9 December 2020; Accepted: 10 December 2020

\begin{abstract}
Utilization of amply available lignocellulosic biomass for a cost-effective conversion to renewable chemicals has proven more difficult than anticipated. Sustainable and viable fractionation of any biomass to its individual monomeric components for their further conversion to products at commercial scale therefore remains elusive. A rapid and scalable multi-step pretreatment strategy for fractionation of rice straw using a combination of dilute aqueous acid and aqueous alkali treatment steps under subcritical conditions was investigated. The process steps and parameters were optimized for yield and purity of the resulting biomass components. Effects of acid and alkali concentrations on the fractionation efficiency were studied in the range of $0.2 \%$ to $12 \% \mathrm{w} / \mathrm{v}$ at temperatures ranging from $110^{\circ} \mathrm{C}$ to $200^{\circ} \mathrm{C}$ for time spanning from 15 to $30 \mathrm{~min}$. The simple optimum sequence of operations and conditions was found to be a diluteacid hydrolysis step at $130^{\circ} \mathrm{C}$ for $15 \mathrm{~min}$ with $2 \% \mathrm{HNO}_{3}$ followed by the second treatment step at $130^{\circ} \mathrm{C}$ for 15 min with $2 \% \mathrm{NaOH}$. This combination gave $90 \%$ pure cellulose in more than $80 \%$ overall yield. Formation of furfurals in the hydrolysate was prevented significantly, and the cellulose obtained showed good amenability for enzymatic hydrolysis to sugars. The same process was applied to wheat straw and sugarcane bagasse, and the obtained results were found to be similar to those obtained for rice straw. The process was successfully scaled up to $50 \mathrm{~L}$ batch process with negligible deviations from smaller scale run results.
\end{abstract}

Keywords: lignocellulosic, biomass, pretreatment, biomass fractionation, cellulose

\section{Symbols}

LBM Lignocellulosic Biomass

NREL National Renewable Energy Laboratory

CrI Crystallinity Index

$I_{002} \quad$ Intensity of peak in X-Ray Diffraction (XRD) chromatogram corresponding to 002 peak of cellulose

$I_{A M} \quad$ Intensity of peak in XRD chromatogram corresponding to amorphous peak of cellulose

$2 \theta \quad$ Diffraction angle in X-Ray diffractometer

IWS Initial Wheat Straw

AM Amorphous

Copyright (C)2021 Lali Mallinath Arvind, et al.

DOI: https://doi.org/10.37256/sce.222021782

This is an open-access article distributed under a CC BY license

(Creative Commons Attribution 4.0 International License)

https://creativecommons.org/licenses/by/4.0/ 


\section{Introduction}

Lignocellulosic biomass (LBM) has the potential to emerge as renewable raw material for all needs presently served by coal and petroleum resources. LBM may comprise of leaf, stem, and root of plants i.e. the anatomically vascular and structural parts of the plants, primarily made up of around $70 \%$ sugars (typically $35-55 \%$ cellulose and $20-45 \%$ hemicellulose) and $10-25 \%$ phenolic polymers as lignin, with additional $5-15 \%$ of extractives, $1-15 \%$ of ash and $1-10 \%$ of other organic components including proteins, alkaloids, etc. The major LBM components, if dissociated, depolymerized, and isolated in purity, can be individually converted to an increasing range of products through chemocatalytic or bio-catalytic routes. Further, if biomass can be depolymerized to high purity glucose in high yields, such a process can potentially replace the production of edible sugars from resource intensive and dedicated crops like sugarcane, sugar beet, cassava, and corn.

Obtaining the individual LBM components in high monomeric purity is often important for designing their chemical or biochemical transformations to products of interest. Many attempts have been made to design one or the other combinations of physical, thermal, chemical, and biological methods for depolymerizing and fractionating lignocellulosic biomass. ${ }^{1}$ The main hurdle has been the structural complexity and recalcitrance of LBM, making it difficult to either fractionally and selectively dissociate to extract pure individual components, or to separate the multiple components after the complete composite breakdown. Either way, this necessitates designing steps in a way as to not only open up the biomass structure but also dissociate the components by $\mathrm{C}-\mathrm{O}$ and $\mathrm{C}-\mathrm{C}$ cleavages through stepwise hydrolyzing and solubilizing of the components. This progression of steps can each be also designed to assist the following step by increasing exposure of the residual components through increasing porosity and altering the cellulosic crystal structure. Further, since biomass pretreatment process is the more cost-intensive step in a biomass biorefinery, it is important that any designed combination of steps is scalable and cost effective. ${ }^{1,2}$

Biomass can be treated by different combination of methods often depending upon the final desired outcomes. For example, composite biomass deconstruction for direct next step use without fractionation (e.g. simultaneous saccharification and fermentation, SSF), and obtaining individual monomeric components require different approaches. The primary focus nevertheless is always on breaking inter-polymer and intra-polymer C-O and C-C bonds. Physical treatments have involved energy-consuming mechanical shearing, milling, grinding, chopping, etc. that help defibrillation thus enhancing the accessibility of biomass to chemical reagents and enzymes. ${ }^{3,4}$ Thermo-mechanical treatment like extrusion cooking, which is a combination of screw grinding with heating exchange system, is reported to enhance accessibility by twofold and reducing the retention time substantially. ${ }^{5}$ Better accessibility to hydrolyzing agents helps reduce reaction times and may also reduce the formation of inhibitory byproducts like furfural and 5-hydroxymethyl furfural (HMF). ${ }^{6}$ Irradiation techniques including microwave, ultrasound, pulsed electric field, and $\beta$-irradiation have also been suggested but are not considered scalable to expected levels of operations in a commercial biorefinery. ${ }^{6-11}$

Chemical pretreatments have involved acidic reagents, basic reagents, and solvents, used either at ambient conditions or at elevated temperature and pressure conditions. Mineral acids like sulfuric acid, nitric acid, hydrochloric acid, and phosphoric acid have been reported to hydrolyze major fractions of mixed sugars into liquid streams. However, multistep pretreatment shows better results at obtaining relatively pure and individual monomeric sugar streams than a single step pretreatment. ${ }^{12}$ Dottori et al. patented a continuous two-stage process for conversion of comminuted LBM with steam and up to $5 \%$ acid, at around $200^{\circ} \mathrm{C}$ for $2 \mathrm{~h}$, followed by treatment with $1: 1$ ethanol-water mixture for 2 h to get $80 \%$ pure cellulose with up to $10 \%$ of hemicellulose and $8 \%$ of lignin as impurities. ${ }^{13}$ High pH pretreatment using $\mathrm{NaOH}, \mathrm{KOH}, \mathrm{Ca}(\mathrm{OH})_{2}$, ammonia and hydrazine are known to decrease degree of polymerization, cellulose crystallinity, and break the lignin-carbohydrate linkages disrupting the lignin structure. Alkaline conditions also swell the biomass resulting in an increased internal surface area for subsequent reagent actions. ${ }^{14-19}$ Sharma et al. attempted $\mathrm{NaOH}$ pretreatment of rice straw with a maximum $63 \%$ cellulose recovery. ${ }^{19} \mathrm{Kim}$ et al. subjected soybean straw to $2-12 \%$ alkali treatment at $121^{\circ} \mathrm{C}$ for $60 \mathrm{~min}$, at $8 \% \mathrm{NaOH}$ to obtain $74 \%$ cellulose purity with $66 \%$ recovery along with $10.3 \%$ 
hemicellulose and $10.1 \%$ lignin as impurities. ${ }^{20}$ Tsegaye et al. used an open pot approach where comminuted rice straw was subjected to treatment of $1-10 \% \mathrm{NaOH}$ at $1: 10$ solid-liquid ratio at $80^{\circ} \mathrm{C}$ for $4 \mathrm{~h}$. Cellulose in $71.3 \%$ purity was achieved containing $13.5 \%$ hemicellulose with overall $71.2 \%$ delignification. ${ }^{21}$

Ammonia fiber/freeze explosion (AFEX), ammonia recycle percolation (ARP), and soaking aqueous ammonia (SAA) are some of the reported and attempted ammonia-based pretreatment methods at scale. ARP reportedly selectively delignifies $70-85 \%$ of corn stover lignin within 20 min of pretreatment while removing $40-60 \%$ hemicellulose without affecting cellulose content. ${ }^{22}$ Phitsuwan et al. subjected rice straw to aqueous ammonia treatment in two different steps of different temperatures, viz. room temperature and $60^{\circ} \mathrm{C}$, for 3 days incubation period. ${ }^{23}$ Cellulose in only $44.3 \%$ purity with $93.6 \%$ recovery was achieved with $60.7 \%$ delignification and $27.9 \%$ hemicellulose removal. While these single-step pretreatments are better in terms of increasing biomass accessibility, they fail in sufficiently fractionating the components.

Fan et al. treated comminuted rice straw with a two-step pretreatment that included $4 \% \mathrm{KOH}$ at $40^{\circ} \mathrm{C}$ for $8 \mathrm{~h}$ then $90^{\circ} \mathrm{C}$ for $4 \mathrm{~h}$, followed by acetic acid $(\mathrm{pH} 3-4)$ at $70^{\circ} \mathrm{C}$ for $6 \mathrm{~h}$ to obtain $85 \% \mathrm{w} / \mathrm{w}$ purity of cellulose. ${ }^{24}$ Wingerson claimed isolation of up to $98 \%$ of cellulose recovery with $92.4 \%$ purity along with about $3.3 \%$ and $3.8 \%$ of lignin and ash, respectively in a two-step pretreatment. ${ }^{25}$ In step 1, sawdust was treated under 24 bar steam pressure at $220^{\circ} \mathrm{C}$ for $10 \mathrm{~min}$, followed by second step of hot alkaline solution of $\mathrm{pH} 8-13$ at around $220^{\circ} \mathrm{C}$. Karstens claimed obtaining $93 \%$ pure cellulose with about $40 \%$ total residue recovery (which may correspond to $>90 \%$ cellulose yields) with $6.1 \%$ xylose as impurity, with 2-stage steam and amine-based process wherein LBM straw was minced and subjected to prehydrolysis at $170^{\circ} \mathrm{C}$ for 120 min under 7 bar of steam pressure. ${ }^{26}$ The residue thus generated was subjected to dilute monoethanolamine in a ratio of $1: 6.5$ and subjected to $160^{\circ} \mathrm{C}$ for $30 \mathrm{~min}$. Jaisamut et al. in 2016 treated wheat straw with combination of $1 \% \mathrm{H}_{2} \mathrm{SO}_{4}$, and $2.4 \% \mathrm{Na}_{2} \mathrm{SO}_{3}$ at $180^{\circ} \mathrm{C}$ for $30 \mathrm{~min}, 80 \%$ of the cellulose conversion into glucose was observed. ${ }^{27}$ Dziekońska-Kubczak et al. in 2019 treated Jerusalem artichoke stalks (JAS) and oat straw (OS) with acid $\left(\mathrm{H}_{2} \mathrm{SO}_{4}, \mathrm{HNO}_{3}\right)$ and alkali $(\mathrm{NaOH})$ in the alternate sequence of treatments in the range of $(2 \%$ and $5 \% \mathrm{w} / \mathrm{v})$ to achieve $89.6 \%$ cellulose purity. ${ }^{12}$

Organosolv process is another evolving pretreatment option, and involves solvation of the components of LBM into aqueous organic solvents like ethanol, methanol, acetone, ethylene glycol, etc., aided with temperature (up to $200^{\circ} \mathrm{C}$ ), pressure and catalytic conditions for selective solubilization of components, common catalysts attempted have included acid, base and salts. ${ }^{28}$ Ample work is done on solubilizing lignin, which is increasingly being considered a potential value-added product. Mesa et al. treated sugarcane bagasse by a combined dilute acid pretreatment following $30 \% \mathrm{v} / \mathrm{v}$ ethanolic alkali (ethanol-water mixture) at $195^{\circ} \mathrm{C}$ for $60 \mathrm{~min}$ to yield $87.29 \%$ cellulose recovery hydrolyzed to $67.3 \%$ glucose. ${ }^{29}$ Danny $\mathrm{C}$ et al. subjected Napier grass to organosolv treatment using aqueous solution of ethylene glycol and 1-pentane in the range of $50-70 \% \mathrm{v} / \mathrm{v}$ at $95^{\circ} \mathrm{C}$ for $60 \mathrm{~min}$ under atmospheric pressure. Best results were obtained at $50 \% \mathrm{v} / \mathrm{v}$ ethylene glycol: water mixture as a solvent with around $83.4 \%$ delignification and $70.1 \% \alpha$-cellulose recovery, $97.9 \%$-cellulose and hemicellulose recovery. ${ }^{30}$ Danny et al. in another work utilized alkaline ethylene glycol for organosolv pretreatment of degraded empty fruit bunch (DEFB) to isolate cellulose. Best results were obtained by treatment of DEFB with $50 \% \mathrm{v} / \mathrm{v}$ aqueous ethylene glycol: $3 \% \mathrm{v} / \mathrm{v} \mathrm{NaOH}$ mixture at $80^{\circ} \mathrm{C}$ for 30 min with $92.9 \%$ cellulose recovery, $48.2 \%$ delignification and $54.4 \%$ hemicellulose removal. ${ }^{31}$ Panagiotopoulos et al. treated poplar wood chips in a 2 stage treatment with steam followed by organosolv for fractionating components resulting in $98 \%$ cellulose recovery hydrolyzed to $88 \%$ glucose and $66 \%$ lignin extraction in $72 \mathrm{~h}^{32}$ Tang et al. achieved $100 \%$ cellulose recovery with $76 \%$ purity by pretreatment of rice straw with mono ethylene glycol (MEG) and $\mathrm{AlCl}_{3}$ mixture, along with around $88 \%$ delignification and $90 \%$ hemicellulose removal. The optimum parameters were $0.2 \mathrm{M} \mathrm{AlCl}_{3}$ in $90 \%$ aqueous MEG with $5 \%$ biomass loading at $150^{\circ} \mathrm{C}$ for $30 \mathrm{~min}^{33}$ However, factors like use of expensive solvents, operational hazards like flammability and toxicity, solvent recovering and recycling efficiency have limited the scope of commercial applications of most of these reported methods. ${ }^{34}$

Despite much work on the several pre-treatment options, demonstration plants and commercial-scale plants designed and commissioned in the last two decades have predominantly used physico-chemical treatments. Solventbased processes have been not popular due to the cost factor from the cost and loss of solvents in processing that essentially involves complex filtration steps. As low as $1 \%$ loss of solvent has been seen to result in a steep rise in the cost of production of cellulosic sugars. On the other hand, while physico-chemical pretreatment approach is a more cost effective and scalable option; it is generally believed that each biomass variety needs detailed investigation and optimization for optimal results. It is also amply established now that none of the treatments alone by itself is able to 
cost effectively isolate pure fraction of any of the biomass components. Pretreatment processes are generally intended to open up the complex matrix rather than effect selective extraction of components. A non-selective treatment while may make the biomass amenable to deconstruction catalysts like enzymes, but results in a mixture of compounds. The resulting bulk cocktail of compounds requires intensive purification procedures in the event of the requirement of pure monomers. Therefore, when the requirement is for pure glucose, xylose, or lignin, it may be preferable to fractionate the biomass components to the extent possible. A combination of physico-chemical treatments in a sequential manner may be able to selectivity isolate pure fractions and reduce the need for downstream processing for purifications. If done in a scale and cost-effective manner, such a process may hold immense potential for creating renewable bio-economies.

Pure cellulose serves as raw material and precursor for a wide spectrum of chemicals that find use in a wide range of applications. Examples are applications in polymers as rayon, lyocell, modal, alkylated cellulose, silicified cellulose; in pharmaceuticals as microcrystalline cellulose, fillers, excipient, diluents, binders, etc.; in foods as bulking agents, emulsifies, texturizer, extenders, probiotics, dietary fibers, potable glucose; and further derivatives like sorbitol and mannitol. Other bulk molecules that can be synthesized from cellulose include short-chain polyols, carboxylate, and a range of cellulose derivatives which find applications in creating bio-degradable polymers, surfactants, dyestuffs, etc.

The objective of the present work was to devise a platform process that would be able to remove hemicellulose, lignin, ash, and other extractive components of any biomass and retain as solid the major fraction of cellulose in high purity. It was desirable to use a multistep but carefully designed physico-chemical treatment approach that would provide more than $90 \%$ pure cellulose in more than $80 \%$ yield based on cellulose present in raw biomass. A combination of otherwise traditional pre-treatment steps was used involving the use of dilute aqueous acid and alkali under subcritical conditions.

\section{Materials and methods}

\subsection{Chemicals, reagents and instruments used}

Rice straw and wheat straw were obtained from Kashipur, India. Corncob and corn stover were obtained from farm fields of Pune and Solapur, India. Sugarcane bagasse was locally sourced within Mumbai, India. Open-air sun-dried biomass samples were ground on a rotary shear grinder (Premium Pullman, India) and sieved to the particle size range of 100-600 $\mu \mathrm{m}$. Representative samples were subjected to compositional analysis for sugars and lignin according to NREL Method 42618. ${ }^{35}$

Equipment used for the biomass sample processing for analysis included XM 60-HR Moisture Analyzer, Thermolyne ${ }^{\mathrm{TM}}$ Benchtop $1100^{\circ} \mathrm{C}$ Muffle Furnace, Arium ${ }^{\circledR} 611$ Ultrapure Type 1 DI Water System. All experiments were conducted using borosilicate glassware.

Reagent grade $\mathrm{H}_{2} \mathrm{SO}_{4}, \mathrm{HNO}_{3}, \mathrm{NaOH}$, and $\mathrm{CaCO}_{3}$ were purchased from SD Fine-Chem, India. Analytical grade D-(+)-glucose, D-(-)-fructose, D-(+)-xylose, HMF, furfural, levulinic acid, formic acid, acetic acid were purchased from Sigma-Aldrich, India.

\subsection{Multiple step pretreatment}

Ground rice straw was subjected to alkali treatment in the range $1 \% \mathrm{w} / \mathrm{v}$ to $12 \% \mathrm{w} / \mathrm{v} \mathrm{NaOH}$, in a microwave digester (Biotage Initiator using $20 \mathrm{~mL}$ sealable glass vials) in the temperature range of $110^{\circ} \mathrm{C}$ to $190^{\circ} \mathrm{C}$ for time ranging from 15 to $30 \mathrm{~min}$ with the solid to liquid ratio of 1:10. The slurry was prepared with powdered biomass and then subjected to reaction at desired parameters. After completion of the step, the vial was rapidly cooled to $60^{\circ} \mathrm{C}$ and vacuum filtered through $0.11 \mu \mathrm{m}$ filtration nylon cloth. The residue was washed with de-ionized (DI) water till neutral $\mathrm{pH}$, dried in the air, and stored in the sealed bags for analysis. The same procedure was adopted for aqueous acid treatment as the first step using nitric acid in the concentration range of 0.1 to $3 \% \mathrm{w} / \mathrm{v}$ acid.

The washed residue from the $1^{\text {st }}$ step typically containing $70-80 \% \mathrm{w} / \mathrm{w}$ moisture, was transferred to another $20 \mathrm{~mL}$ vial and subjected to another alkali or acid treatment, in different concentrations in the same range used in the $1^{\text {st }}$ step. After the $2^{\text {nd }}$ step, the residue was again washed with DI water till neutral $\mathrm{pH}$, dried in the air, and stored in the sealed bags for analysis. The solid residue after each step was analyzed for its composition and mass. 
In order to limit the excessively large number of experiments, the $1^{\text {st }}$ step with alkali and acid was optimized for all the feedstock samples i.e. rice straw, wheat straw, corn stover, corncob, and sugarcane bagasse. The $2^{\text {nd }}$ step was however optimized only for rice straw and the final optimized steps then applied to wheat straw and sugarcane bagasse.

The optimized process for rice straw was then scaled up to $400 \mathrm{~mL}$ electrically heated jacketed pressure stirred reactor and equipped with quick water cooling (Amar Equipment, India). The reactions for alkali were performed under 5 bar nitrogen pressure while acidic pretreatment was performed under 10 bar.

The system was further scaled up to $5 \mathrm{~L}$ electrically heated pressure reactor (Snowtech Equipment, India); and then to a $50 \mathrm{~L}$ steam-heated pressure reactor (courtesy Privi Specialty Chemicals Limited, Mahad).

\subsection{Biomass and product analysis}

\subsubsection{Analysis of solid samples}

Solid biomass samples generated before and after the treatment were vacuum dried and analyzed for carbohydrates and lignin following every step of pretreatment according to NREL protocol $42618 .{ }^{35}$ Precisely, $300.0 \pm 1.0 \mathrm{mg}$ of a dried sample was quantitatively digested in $3 \mathrm{~mL} \mathrm{72 \% (w/w)} \mathrm{aqueous} \mathrm{H}_{2} \mathrm{SO}_{4}$, and incubated for $1 \mathrm{~h}$ under constant stirring. $84 \mathrm{~mL}$ of DI water was added and the solution was subjected to autoclave conditions at $121^{\circ} \mathrm{C}$ for $1 \mathrm{~h}$. The solution was quantitatively filtered through a pre-weighed sintered glass crucible to collect all insoluble fraction in the crucible, while liquid fraction was neutralized with calcium carbonate and subjected to quantification by HPLC method using Agilent 1200 series HPLC equipped with refractive index detector and Aminex HPX-87H $300 \times 7.8 \mathrm{~mm}$ (BioRad) column. $1 \mu \mathrm{L}$ of the sample was injected, and samples were analyzed using $5 \mathrm{mM} \mathrm{H}_{2} \mathrm{SO}_{4}$ as the mobile phase at $0.6 \mathrm{~mL} / \mathrm{min}$ of flow rate, $65^{\circ} \mathrm{C}$ column temperature, $35^{\circ} \mathrm{C}$ refractive index detector (RID) temperature, and run time of $60 \mathrm{~min}$. Each sample was analyzed in duplicate. Insoluble residual fractions were analyzed for acid insoluble lignin and ash gravimetrically by drying the solids in a crucible at $105^{\circ} \mathrm{C}$ for $3 \mathrm{~h}$ and weighing, followed by calcination at $575^{\circ} \mathrm{C}$ for $18 \mathrm{~h}$ and weighing. The weight difference between weight after calcination at $575^{\circ} \mathrm{C}$ and dry weight after $105^{\circ} \mathrm{C}$ corresponds to acid insoluble lignin, while the weight difference between weight after $575^{\circ} \mathrm{C}$ and initial weight of the crucible corresponds to the weight of the ash.

Initial compositions of the biomass used in the work, averaged over three estimations, are given in Table 1.

Table 1. Compositional analysis of ground lignocellulosic biomass varieties on dry basis

\begin{tabular}{|c|c|c|c|c|c|c|c|}
\hline \multirow{2}{*}{ Sr. No. } & \multirow{2}{*}{ Biomass } & \multicolumn{5}{|c|}{ Component present $(\% \mathrm{w} / \mathrm{w})$} & \multirow{2}{*}{$\begin{array}{c}\text { Total } \\
(\% \mathrm{w} / \mathrm{w})\end{array}$} \\
\hline & & Glucose & Xylose & Arabinose & Lignin & Ash & \\
\hline 1 & Rice straw & 40.38 & 23.88 & 3.65 & 15.49 & 9.79 & 93.19 \\
\hline 2 & Wheat straw & 40.25 & 18.79 & 2.49 & 19.96 & 2.83 & 84.32 \\
\hline 3 & Sugarcane bagasse & 50.25 & 24.72 & 1.76 & 19.06 & 1.68 & 97.47 \\
\hline 4 & Corncob & 45.61 & 37.05 & 3.97 & 8.53 & 2.97 & 98.13 \\
\hline 5 & Corn stover & 41.65 & 26.37 & 3.94 & 22.45 & 1.40 & 95.81 \\
\hline
\end{tabular}

\subsubsection{Characterization of initial and residual biomass}

In order to evaluate the influence of each step of the sequential fractionation process on biomass composition and structure, the initial biomass and residues were also analyzed by Fourier Transform Infrared (FTIR) spectroscopy and XRD analysis.

Initial wheat straw and residues generated by treatment at optimum parameters at $5 \mathrm{~L}$ batch scale were screened for XRD and FTIR analysis to evaluate crystallinity and elucidate structural changes. The powder X-ray diffractometer

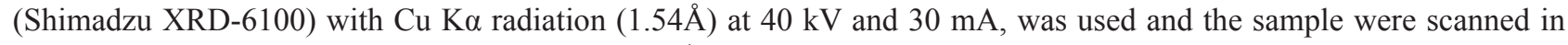
the $2 \theta$ angle range of $5^{\circ}$ to $50^{\circ}$ at the rate of $2^{\circ} \mathrm{min}^{-1}$. The crystallinity index $(\mathrm{CrI})$ was calculated according to the Segal equation. $^{36}$ 
The crystallinity index (\%) was calculated to evaluate the structural changes in correlation with the pretreatment. The chromatograms were de-convoluted in order to determine more accurate values of the crystallinity index. The deconvolution was performed on raw data using Microsoft (MS) Excel Solver 2010 considering Gaussian function to resolved individual peak. The crystallinity index was calculated for raw as well as de-convoluted and equated peaks, using the Segal equation.

$$
C_{r I}(\%)=\left(\frac{I_{002}-I_{A M}}{I_{002}}\right) \times 100
$$

Where, $I_{002}$ is diffraction intensity at $2 \theta$ maxima around $20^{\circ}$ to $24^{\circ}$ and $I_{A M}$ is the $2 \theta$ minima between $15^{\circ}$ and $20^{\circ}$. The raw and de-convoluted XRD patterns obtained are plotted in Figure 1 and Figure 2, respectively and the CrI values calculated are given in Table 16.

The FTIR analysis was performed using Infrared (IR) equipment (Shimadzu IR Prestige 21) equipped with an attenuated total reflection (ATR) sample holder. Samples were scanned in the range of 5000-500 $\mathrm{cm}^{-1}$ with 40 iterations. Raw data were processed with ATR correction and Spectrum Normalization. The spectrograms are plotted in Figure 3, and the interpretations are presented in Table 10.

\section{Results and discussion}

The chemistry of biomass deconstruction using acid and alkali is now well known for decades. The basic idea is to hydrolyze ester and ether bonds in biomass structure while also overcome strong hydrogen bonds and pi bonds between and within biomass components viz. cellulose, hemicellulose, and lignin often via other minor components. Although there is some variation between structures and composition of the biomass from one feedstock to another, the basic theme remains the same. However, while this variation still offers challenges in developing a common scalable and robust biomass deconstruction technology, another major issue emerges from the inability of the deconstructing reagents to penetrate the entire biomass structure all at once. Since all of the biomass in a solid particle cannot become at once available to chemical agents, the deconstruction must happen as a combination of two events: (a) peeling of biomass from outer surface inwards, and (b) leaching out of the hydrolyzed biomass components from particle pores. It is easy to imagine that efficacy of deconstruction will depend much on the relative speeds of the two events, and the biomass particle size must play an important role.

The technology for biomass deconstruction becomes more challenging if it is to be aimed at fractional deconstruction of biomass so that individual components cellulose, hemicellulose, and lignin are obtained separately. As stated earlier in this report, a large number of combinations of methods at different acid or alkali concentrations and temperatures have been attempted over different time durations. In this work, two of the more effective and proven chemical agents were used i.e. dilute alkali and dilute nitric acid, the latter especially due to its 'friendliness' to stainless steel reactors. While each of the two agents can hydrolyze biomass substantially under one or the other conditions of time, temperature, and concentration, the idea behind the work was to obtain pure cellulose in high yields and reasonable time, and thus combinations of conditions needed to be explored and which was the pure and simple purpose of this work.

The objective of the work was thus to obtain pure cellulose in the highest possible yield from different biomass feedstock and to ascertain that the obtained cellulose is amenable to enzymatic saccharification in order to be able to obtain glucose. Different treatments with aqueous $\mathrm{NaOH}$ and nitric acid were attempted separately on different biomass feedstock. The choice of alkali and acid for this work was made for many reasons. Dilute aqueous sodium hydroxide and nitric acid solutions are relatively inexpensive and easy to handle chemicals not demanding expensive metallurgy in plant construction. They also afford a possibility of reuse of the bulk of the unreacted reagents if separated from the reaction mass by one or the other physical methods. Further, while soda alkali is known to swell cellulosic residues for better amenability to both chemical and enzymatic attacks, nitric acid has been reported to result in lower formation of furfural derivatives. ${ }^{37}$ 


\subsection{Alkaline fractionation of biomass}

Aqueous $\mathrm{NaOH}$ treatment was primarily selected with an aim of attaining fractionation of biomass into components, under relatively mild conditions. Comminuted rice straw was subjected to alkaline pretreatment at temperatures above $110^{\circ} \mathrm{C}$ which is reported to be the glass transition temperature for hemicellulose and lignin under wetted conditions. A range of $1 \%$ to $13 \%(\mathrm{w} / \mathrm{v})$ alkali concentration was screened for effective solubilization of lignin and hemicellulose. The composition of the residue was estimated by hard acid digestion as per NREL Protocol $42618,{ }^{35}$ and cellulose was estimated as glucose while xylan was estimated as xylose and arabinose as the major constituting sugars. Desired output for experiments was near complete retention of cellulose in residue and solubilization of major faction of xylan and lignin into the aqueous stream. Different $\mathrm{NaOH}$ concentrations were used for the first step treatment at an initial parameter set of $130^{\circ} \mathrm{C}$ to $190^{\circ} \mathrm{C}$ temperature; $30 \mathrm{~min}$ reaction time and $10 \% \mathrm{w} / \mathrm{v}$ biomass loading. The results as obtained on the microwave heated Biotage system at $15 \mathrm{~mL}$ scale are shown in Table 2 and 3, with Table 2 presenting the composition of the treated residue and Table 3 presenting the yields of the respective components based on initial contents.

Table 2. Effect of $\mathrm{NaOH}$ concentration and temperature on rice straw residue composition after treatment for $30 \mathrm{~min}$ at $10 \% \mathrm{w} / \mathrm{v}$ solid loading in three sets

\begin{tabular}{|c|c|c|c|c|c|c|c|c|}
\hline \multirow{2}{*}{ Expt. No. } & \multirow{2}{*}{$\begin{array}{c}\mathrm{NaOH} \\
(\% \mathrm{w} / \mathrm{v})\end{array}$} & \multirow{2}{*}{$\begin{array}{l}\text { Temperature } \\
\left({ }^{\circ} \mathrm{C}\right)\end{array}$} & \multicolumn{5}{|c|}{ Components present $(\% \mathrm{w} / \mathrm{w})$} & \multirow{2}{*}{$\begin{array}{c}\text { Total } \\
(\% \mathrm{w} / \mathrm{w})\end{array}$} \\
\hline & & & Glucose & Xylose & Arabinose & Lignin & Ash & \\
\hline 1 & & omass & 40.25 & 18.79 & 2.49 & 19.96 & 9.79 & 91.28 \\
\hline \multicolumn{9}{|l|}{ Set 1} \\
\hline 2 & 1 & 130 & 50.61 & 15.28 & 0.29 & 7.72 & 2.13 & 76.02 \\
\hline 3 & 2 & 130 & 54.47 & 15.34 & 0.00 & 6.23 & 1.22 & 77.26 \\
\hline 4 & 5 & 130 & 67.56 & 14.97 & 0.00 & 6.78 & 0.00 & 89.31 \\
\hline 5 & 10 & 130 & 85.93 & 4.77 & 0.33 & 7.31 & 0.92 & 99.27 \\
\hline 6 & 13 & 130 & 85.49 & 4.83 & 0.47 & 6.97 & 0.88 & 98.64 \\
\hline \multicolumn{9}{|l|}{ Set 2} \\
\hline 3 & 2 & 130 & 54.47 & 15.34 & 0.00 & 6.23 & 1.22 & 77.26 \\
\hline 7 & 2 & 150 & 62.56 & 16.98 & 2.44 & 5.90 & 1.43 & 89.31 \\
\hline 8 & 2 & 170 & 69.38 & 16.15 & 1.74 & 5.13 & 1.52 & 93.92 \\
\hline 9 & 2 & 190 & 69.69 & 15.60 & 1.57 & 4.70 & 4.05 & 95.61 \\
\hline \multicolumn{9}{|l|}{ Set 3} \\
\hline 7 & 2 & 150 & 62.56 & 16.98 & 2.44 & 5.90 & 1.43 & 89.31 \\
\hline 10 & 5 & 150 & 72.19 & 16.60 & 0.00 & 4.54 & 1.29 & 94.62 \\
\hline 11 & 10 & 150 & 84.57 & 7.35 & 1.02 & 6.12 & 0.87 & 99.92 \\
\hline
\end{tabular}

Set 1: Five different $\mathrm{NaOH}$ concentrations at $130^{\circ} \mathrm{C}$;

Set 2: $2 \% \mathrm{NaOH}$ at four different temperatures;

Set 3: Three different $\mathrm{NaOH}$ concentrations at $150^{\circ} \mathrm{C}$

Results at $130^{\circ} \mathrm{C}$ i.e. experiment numbers 2-6 in both Table 2 and 3 indicate that increasing concentration of alkali provides increasing delignification up to $10 \%$ alkali. Xylan, a combination of xylose and arabinose, also leaches out increasingly with increasing alkali concentrations up to $10 \%$. Thus, there is a rise in residual cellulose purity up to $10 \%$ alkali but occurs at the expense of loss of cellulose in hydrolysate. The overall results indicate the highest extraction of xylan of about $93 \%$ at $10 \% \mathrm{NaOH}$ at $130^{\circ} \mathrm{C}$ (Table 3, Expt. No. 5). The delignification at this point is also significant at 
about $87 \%$. The maximum purity of residual cellulose fraction was however only about $81 \%$ along with $20 \%$ cellulose loss. On account of cellulose purity not going beyond $81 \%$ accompanied by almost $20 \%$ loss of cellulose, a milder alkali treatment followed by a second step treatment was considered necessary. All the above experiments tabulated in Table 2 and 3 were done in duplicate on microwave heated Biotage system in $15 \mathrm{~mL}$ batches.

Table 3. Effect of $\mathrm{NaOH}$ concentration and temperature on yields of the components in the residue based on starting composition after treatment of rice straw for $30 \mathrm{~min}$ at $10 \% \mathrm{w} / \mathrm{v}$ solid loading-All experiments and sets are the same as in Table 2

\begin{tabular}{|c|c|c|c|c|c|c|}
\hline \multirow{2}{*}{ Expt. No. } & \multicolumn{5}{|c|}{ Yields in residual mass $(\% \mathrm{w} / \mathrm{w})$} & \multirow{2}{*}{$\begin{array}{l}\text { Total weight yield of residue } \\
\qquad(\% \mathrm{w} / \mathrm{w})\end{array}$} \\
\hline & Glucose & Xylose & Arabinose & Lignin & Ash & \\
\hline 1 & & & Biomass & & & \\
\hline \multicolumn{7}{|l|}{ Set 1} \\
\hline 2 & 98.96 & 64.02 & 9.04 & 30.43 & 2.13 & 78.71 \\
\hline 3 & 96.50 & 58.23 & 0.00 & 22.24 & 8.90 & 71.31 \\
\hline 4 & 89.28 & 42.38 & 0.00 & 18.07 & 0.00 & 53.19 \\
\hline 5 & 80.73 & 9.60 & 5.07 & 13.86 & 3.56 & 37.82 \\
\hline 6 & 73.46 & 8.89 & 6.49 & 12.08 & 3.11 & 34.59 \\
\hline \multicolumn{7}{|l|}{ Set 2} \\
\hline 3 & 96.50 & 58.23 & 0.00 & 22.24 & 8.90 & 71.31 \\
\hline 7 & 99.41 & 57.80 & 62.75 & 18.91 & 9.36 & 63.96 \\
\hline 8 & 93.71 & 46.72 & 37.96 & 13.99 & 8.43 & 54.37 \\
\hline 9 & 80.14 & 38.43 & 29.10 & 10.91 & 19.16 & 46.29 \\
\hline \multicolumn{7}{|l|}{ Set 3} \\
\hline 7 & 99.41 & 57.80 & 62.75 & 18.91 & 9.36 & 63.96 \\
\hline 10 & 83.06 & 40.90 & 0.00 & 10.53 & 6.11 & 46.31 \\
\hline 11 & 70.87 & 13.19 & 13.76 & 10.34 & 3.00 & 33.73 \\
\hline
\end{tabular}

The same treatment was carried out on rice straw as well as other varieties of LBM at a larger scale of electrically heated $5 \mathrm{~L}$ pressure reactor, and the results are given in Table 4 and 5. Further, the experiments were also carried out under similar conditions on a jacket steam-heated $50 \mathrm{~L}$ pressure reactor, and the results were the same as those obtained on the $5 \mathrm{~L}$ reactor and hence are not presented again.

Table 4. Compositional analysis of residue from $10 \% \mathrm{w} / \mathrm{v} \mathrm{NaOH}$ treatment to different lignocellulosic biomass varieties at $130^{\circ} \mathrm{C}$ for $30 \mathrm{~min}$ in $5 \mathrm{~L}$ and $50 \mathrm{~L}$ pressure reactor

\begin{tabular}{|c|c|c|c|c|c|c|c|}
\hline \multirow{2}{*}{ Expt. No. } & \multirow{2}{*}{ Biomass } & \multicolumn{5}{|c|}{ Component present $(\% \mathrm{w} / \mathrm{w})$} & \multirow{2}{*}{$\begin{array}{c}\text { Total } \\
(\% \mathrm{w} / \mathrm{w})\end{array}$} \\
\hline & & Glucose & Xylose & Arabinose & Lignin & Ash & \\
\hline 13 & Wheat straw & 84.77 & 5.26 & 0.44 & 6.47 & 0.92 & 97.86 \\
\hline 14 & Sugarcane bagasse & 82.32 & 6.83 & 0.81 & 6.87 & 0.57 & 97.40 \\
\hline 16 & Corn stover & 77.76 & 5.57 & 0.42 & 12.02 & 0.37 & 96.14 \\
\hline
\end{tabular}


Table 5. Yields of components in residue from $10 \% \mathrm{w} / \mathrm{v} \mathrm{NaOH}$ treatment to different lignocellulosic biomass varieties at $130^{\circ} \mathrm{C}$ for $30 \mathrm{~min}$ in $5 \mathrm{~L}$ and $50 \mathrm{~L}$ pressure reactor, in same experiments as in Table 4

\begin{tabular}{cccccccc}
\hline \multirow{2}{*}{ Expt. No. } & Biomass & \multicolumn{3}{c}{ Yields in residual mass (\% w/w) } & \multicolumn{2}{c}{$\begin{array}{c}\text { Total weight yield } \\
\text { of residue } \\
(\% \mathrm{w} / \mathrm{w})\end{array}$} \\
\cline { 3 - 7 } & & Glucose & Xylose & Arabinose & Lignin & Ash & 44.17 \\
\hline 12 & Rice straw & 84.58 & 9.01 & 2.90 & 3.65 & 6.45 & 40.21 \\
13 & Wheat straw & 84.42 & 8.86 & 4.84 & 16.80 & 3.78 & 39.95 \\
14 & Sugarcane bagasse & 81.45 & 11.43 & 8.87 & 17.22 & 2.33 & 42.98 \\
15 & Corncob & 84.26 & 11.30 & 7.54 & 26.94 & 4.83 & 30.49 \\
16 & Corn stover & 76.05 & 9.21 & 4.54 & 30.65 & 1.49 & \\
\hline
\end{tabular}

Alkali helps leaching of lignin from biomass particles by multiple modes of action viz. swelling of biomass fibrils making it more accessible for base-catalyzed hydrolysis of ester bonds between lignin and hemicellulose and between hemicellulose and cellulose. Alkali also forms sodium lignate salts through action on substituted phenols in lignin structures and makes lignin water soluble. These hydrolytic and salt formations are typical reactions that are functions of alkali concentration. However, higher than $10 \%$ alkali also results in hydrolysis of the tougher $\beta-\mathrm{O}-4$ inter-linkages in cellulose and this results in loss of cellulose in lignin fractions.

It was possible to recover the lignin and xylan fractions obtained from alkali treatment by stepwise neutralization of the dark liquor followed by lyophilization of the filtered neutralized aqueous stream. These fractions were seen to be polymeric devoid of monomeric components indicating a lack of depolymerization during alkali treatment which is expected since alkali treatment can only hydrolyze the ester linkages. Hydrolyzing xylan and breaking the lignin polymer can therefore be considered a preferred pathway to higher delignification and xylan extraction to obtain high purity cellulose. Mineral acids are known to hydrolyze both xylan and glucan with sulfuric acid being the most popular choice. Sulfuric acid while on one hand hydrolyses sugars but on the other hand, it dehydrates them causing the formation of humins even under milder conditions thereby lowering sugar yields and creating undesirable impurities that complicate downstream operations. Besides, the use of dilute sulfuric acid is accompanied by issues relating to environment and system metallurgy. Phosphoric acid can be used but is not favored in terms of cost and corresponding yields, while hydrochloric acid is highly corrosive and degrades sugars to great extent. Nitric acid was selected for the acid pretreatment in this work.

\subsection{Acidic fractionation of biomass}

The starting aim of this part of the work was complete fractionation of biomass leaving behind a solid fraction with a primary focus on high recovery of high purity cellulose in a single pretreatment. For reasons discussed above, dilute aqueous acidic pretreatment was screened for single fractionation of LBM. Aqueous nitric acid was used in the range of $0.5 \%$ to $3 \% \mathrm{w} / \mathrm{v}$ at temperatures ranging from $130^{\circ} \mathrm{C}$ to $190^{\circ} \mathrm{C}$. These parameters were selected so as to maintain extraction conditions well above softening temperature of hemicellulose and lignin but significantly lower to the cellulose softening point. ${ }^{38}$ It was expected that amorphous xylan and lignin polymers would get extracted in an aqueous stream leaving cellulose in the residual fraction. The results of pretreatment under the range of conditions carried out in microwave heated Biotage system at $15 \mathrm{~mL}$ scale are given in Table 6 and 7.

Concentrations of nitric acid up to $1 \% \mathrm{w} / \mathrm{v}$ at $130^{\circ} \mathrm{C}$ show selectivity for removal of xylan than any other component, which is evident from the rise in cellulose and lignin content in the composition of residue (Table 6, Expt. Nos. $17 \&$ 18). An increase in acid concentration up to $3 \%$ also resulted in increased delignification up to $70 \%$ (Table 7, Expt. Nos. 19-20). Acid concentrations of 3\% and above had no significant effect on xylan and lignin removal but resulted in the loss of cellulose (Table 7, Expt. No. 20). Since lower acid concentration at $130^{\circ} \mathrm{C}$ showed higher xylan extraction and minimal lignin degradation, higher temperatures were screened for $0.5 \%(\mathrm{w} / \mathrm{v})$ acid concentration in order to get a relatively rich syrup of xylan sugar with minimal lignols (Table 6 and 7, Expt. Nos. 17, 21-23). The results indicate significant xylan extraction along with some lignin, especially at higher temperatures. Analysis of the resulting 
liquid stream however indicated dehydration of sugars to furan derivatives like furfural and HMF and their further degradation products.

Table 6. Effect of aqueous $\mathrm{HNO}_{3}$ treatment of rice straw residue composition for $30 \mathrm{~min}$ at $10 \% \mathrm{w} / \mathrm{v}$ solid loading in two sets

\begin{tabular}{|c|c|c|c|c|c|c|c|c|}
\hline \multirow{2}{*}{ Expt. No. } & \multirow{2}{*}{$\begin{array}{l}\mathrm{HNO}_{3} \\
(\% \mathrm{w} / \mathrm{v})\end{array}$} & \multirow{2}{*}{$\begin{array}{l}\text { Temperature } \\
\left({ }^{\circ} \mathrm{C}\right)\end{array}$} & \multicolumn{5}{|c|}{ Components present $(\% \mathrm{w} / \mathrm{w})$} & \multirow{2}{*}{$\begin{array}{c}\text { Total } \\
(\% \mathrm{w} / \mathrm{w})\end{array}$} \\
\hline & & & Glucose & Xylose & Arabinose & Lignin & Ash & \\
\hline \multicolumn{9}{|l|}{ Set 1} \\
\hline 17 & 0.5 & 130 & 51.92 & 14.82 & 0.00 & 22.81 & 4.43 & 93.98 \\
\hline 18 & 1.0 & 130 & 65.97 & 6.81 & 0.00 & 19.30 & 0.53 & 92.61 \\
\hline 19 & 2.0 & 130 & 68.31 & 10.12 & 0.45 & 11.46 & 6.28 & 96.63 \\
\hline 20 & 3.0 & 130 & 69.25 & 10.48 & 0.00 & 11.93 & 3.55 & 95.21 \\
\hline \multicolumn{9}{|l|}{ Set 2} \\
\hline 17 & 0.5 & 130 & 51.92 & 14.82 & 0.00 & 22.81 & 4.43 & 93.98 \\
\hline 21 & 0.5 & 150 & 63.35 & 11.48 & 0.80 & 17.79 & 3.23 & 96.64 \\
\hline 22 & 0.5 & 170 & 59.87 & 8.72 & 0.00 & 19.23 & 2.14 & 89.95 \\
\hline 23 & 0.5 & 190 & 61.55 & 3.21 & 0.27 & 14.22 & 10.75 & 90.00 \\
\hline
\end{tabular}

Set 1: Four different $\mathrm{HNO}_{3}$ concentrations at $130^{\circ} \mathrm{C}$;

Set 2: $0.5 \% \mathrm{HNO}_{3}$ at four different temperatures

Table 7. Effect of aqueous $\mathrm{HNO}_{3}$ treatment of rice straw on yields of components in residue after treatment for $30 \mathrm{~min}$ at $10 \% \mathrm{w} / \mathrm{v}$ solid loading-All experiments and sets are same in Table 6

\begin{tabular}{ccccccc}
\hline \multirow{2}{*}{ Expt. No. } & \multicolumn{5}{c}{ Yields in residual mass $(\% \mathrm{w} / \mathrm{w})$} & \multirow{2}{*}{$\begin{array}{c}\text { Total weight yield of } \\
\text { residue } \\
(\% \mathrm{w} / \mathrm{w})\end{array}$} \\
\cline { 2 - 5 } Set 1 & Glucose & Xylose & Arabinose & Lignin & Ash & \\
17 & 89.62 & 54.81 & 0.00 & 79.41 & 31.44 & 69.48 \\
18 & 90.92 & 20.10 & 0.00 & 53.63 & 3.03 & 55.47 \\
19 & 89.75 & 28.49 & 9.56 & 30.37 & 33.94 & 52.88 \\
20 & 82.48 & 26.74 & 0.00 & 28.65 & 17.38 & 47.94 \\
Set 2 & & & & & & \\
17 & 89.62 & 54.81 & 0.00 & 79.41 & 31.44 & 69.48 \\
21 & 89.74 & 34.82 & 18.22 & 50.82 & 18.81 & 57.02 \\
22 & 85.02 & 26.51 & 0.00 & 55.07 & 12.48 & 57.16 \\
23 & 82.67 & 9.25 & 5.86 & 38.52 & 0.00 & 54.07 \\
\hline
\end{tabular}

It is a general observation that alkali treatment favors hemicellulose and lignin removal in their polymeric forms, while acidic treatment tends to hydrolyze the amorphous polymers to monomers or oligomers of xylan and lignin via hydrolysis of acetal linkages in sugar polymers and ether linkage in lignin polymer, along with acid-catalyzed ester hydrolysis. Acidic treatment, therefore, is more likely to hydrolyze sugar polymers, however in the acid concentration used in this work dissolution of cellulose crystallites does not occur. Thus, the extent of cellulose leach out is limited, while major fractions of xylan and lignin are found to be extracted in acid hydrolysates.

In line with the explanation above, it can be observed that acidic hydrolysis of sugar and lignin polymers have a direct relation with temperature and acid concentration, with the preference of extraction being observed to be: 
Hemicellulose hydrolysis and extraction $>$ Lignin breakdown $>$ Cellulose hydrolysis. Thus, cellulose is observed to be least hydrolyzed under the conditions used in this work.

As evident from the results of set 1 of Table 6 and 7, lower concentration of acid favor hemicellulose removal which can be attributed to the hydrolysis of acetal linkages of amorphous sugars polymers under mild acidic conditions at the working temperature. Higher acid concentration above 1\%, results in a greater degree of lignin breakdown through hydrolysis of C-O-C linkages.

Acid concentrations of $3 \%$ and above have no significant effect on xylan and lignin removal compared to $2 \%$ but have a greater tendency of hydrolyzing cellulose, which can be seen from the drop in the residual cellulose content. The underlying cause may be the incremental rate of dissociation of cellulose crystallite and further hydrolysis with rising acid concentration, at working temperature.

Results of set 2 of Table 6 and 7 indicate that the xylan content reduces linearly as the function of temperature. Sugars are known to dehydrate to furanic moieties which are known to further polymerize with lignin fractions, leading to incremental lignin content at $170^{\circ} \mathrm{C}$, which further hydrolyses at temperatures in the range of $190^{\circ} \mathrm{C}$. Cellulose purity show linear drop above $150^{\circ} \mathrm{C}$, with substantial xylan and lignin breakdown and humins formation, hence the temperatures above $150^{\circ} \mathrm{C}$ were not preferred for studies.

The results above indicate that the single-step $\mathrm{HNO}_{3}$ pretreatment is not able to remove either xylan or lignin sufficiently. However, around $\sim 70 \%$ of both xylan and lignin were extracted by $2 \% \mathrm{HNO}_{3}$ treatment at $130{ }^{\circ} \mathrm{C}$ for 30 min. The same treatment at $5 \mathrm{~L}$ pressure reactor was used on other varieties of LBM and the results are given in Table 8 and 9.

Table 8. Compositional analysis of biomass residues after $2 \% \mathrm{w} / \mathrm{v} \mathrm{HNO}_{3}$ treatment at $130^{\circ} \mathrm{C}$ for $30 \mathrm{~min}$ at $5 \mathrm{~L}$ scale

\begin{tabular}{|c|c|c|c|c|c|c|c|}
\hline \multirow{2}{*}{ Expt. No. } & \multirow{2}{*}{ Biomass } & \multicolumn{5}{|c|}{ Component present $(\% \mathrm{w} / \mathrm{w})$} & \multirow{2}{*}{$\begin{array}{c}\text { Total } \\
(\% \mathrm{w} / \mathrm{w})\end{array}$} \\
\hline & & Glucose & Xylose & Arabinose & Lignin & Ash & \\
\hline 24 & Rice straw & 70.88 & 7.80 & 0.65 & 11.08 & 6.43 & 96.84 \\
\hline 25 & Wheat straw & 68.53 & 11.23 & 0.94 & 11.46 & 0.90 & 93.06 \\
\hline 26 & Sugarcane bagasse & 68.09 & 11.00 & 0.00 & 12.05 & 3.59 & 94.73 \\
\hline 27 & Corncob & 64.98 & 10.47 & 0.00 & 21.55 & 1.01 & 98.10 \\
\hline 28 & Corn stover & 43.32 & 7.01 & 0.46 & 34.00 & 0.34 & 85.13 \\
\hline
\end{tabular}

Table 9. Yields of individual components in residue from $2 \% \mathrm{w} / \mathrm{v} \mathrm{HNO}_{3}$ treatment at $130^{\circ} \mathrm{C}$ for $30 \mathrm{~min}$ at $5 \mathrm{~L}$ scale in same experiments as Table 8

\begin{tabular}{|c|c|c|c|c|c|c|}
\hline \multirow{2}{*}{ Expt. No. } & \multicolumn{5}{|c|}{ Yields in residual mass $(\% \mathrm{w} / \mathrm{w})$} & \multirow{2}{*}{$\begin{array}{l}\text { Total weight yield of residuc } \\
(\% \mathrm{w} / \mathrm{w})\end{array}$} \\
\hline & Glucose & Xylose & Arabinose & Lignin & Ash & \\
\hline 24 & 89.22 & 16.60 & 9.05 & 36.36 & 33.88 & 50.83 \\
\hline 25 & 87.84 & 24.34 & 13.33 & 38.29 & 4.86 & 51.76 \\
\hline 26 & 80.05 & 21.87 & 0 & 36.93 & 17.41 & 47.48 \\
\hline 27 & 79.64 & 23.77 & 0 & 78.43 & 5.56 & 49.50 \\
\hline 28 & 48.46 & 13.24 & 5.69 & 99.41 & 1.71 & 45.17 \\
\hline
\end{tabular}

Since none of the two single steps were suitable for complete isolation of cellulose, it was decided to attempt two step treatment. 


\subsection{Study of effect of $2^{\text {nd }}$ step acidic pretreatment to residue of $1^{\text {st }}$ step acid treatment}

The first treatment was now primarily aimed at softening the biomass having certain fractions of components leach out, and leaving the residual biomass comparatively more porous and accessible to the next step; and hence lower acid concentrations could possibly be used in the second step. Acid concentrations in the range of $0.25 \%-2 \% \mathrm{w} / \mathrm{v} \mathrm{HNO}$ were selected for the second step treatment and used in the temperature range of $130-170^{\circ} \mathrm{C}$ for $30 \mathrm{~min}$. The results are shown in Table 10 and 11.

Table 10. Effect of $\mathrm{HNO}_{3}$ concentration and temperature on residue of the $1^{\text {st }}$ step $\mathrm{HNO}_{3}$ pretreatment of rice straw obtained from experiment no. 24; in the second treatment for $30 \mathrm{~min}$ at $7 \% \mathrm{w} / \mathrm{v}$ solid loading in three sets

\begin{tabular}{|c|c|c|c|c|c|c|c|c|c|}
\hline \multirow{2}{*}{ Expt. No. } & \multirow{2}{*}{ Biomass } & \multirow{2}{*}{$\begin{array}{l}\mathrm{HNO}_{3} \\
(\% \mathrm{w} / \mathrm{v})\end{array}$} & \multirow{2}{*}{$\begin{array}{l}\text { Temp } \\
\left({ }^{\circ} \mathrm{C}\right)\end{array}$} & \multicolumn{5}{|c|}{ Components present $(\% \mathrm{w} / \mathrm{w})$} & \multirow{2}{*}{$\begin{array}{c}\text { Total } \\
(\% \mathrm{w} / \mathrm{w})\end{array}$} \\
\hline & & & & Glucose & Xylose & Arabinose & Lignin & Ash & \\
\hline \multicolumn{10}{|l|}{ Set 1} \\
\hline 29 & \multirow{3}{*}{$\begin{array}{l}\text { Residue of } \\
\text { Expt. No. } 24\end{array}$} & 0.5 & 130 & 63.66 & 2.53 & 0.40 & 11.64 & 9.88 & 88.11 \\
\hline 30 & & 1 & 130 & 69.57 & 5.40 & 0.30 & 10.85 & 1.33 & 87.44 \\
\hline 31 & & 2 & 130 & 71.56 & 6.35 & 0.31 & 6.50 & 6.37 & 91.10 \\
\hline \multicolumn{10}{|l|}{ Set 2} \\
\hline 32 & \multirow{3}{*}{$\begin{array}{l}\text { Residue of } \\
\text { Expt. No. } 24\end{array}$} & 0.5 & 150 & 69.75 & 1.94 & 0.30 & 12.95 & 11.15 & 96.09 \\
\hline 33 & & 1 & 150 & 75.85 & 5.22 & 0.48 & 11.62 & 0.07 & 93.24 \\
\hline 34 & & 2 & 150 & 81.64 & 4.93 & 0.67 & 10.46 & 2.97 & 100.66 \\
\hline \multicolumn{10}{|l|}{ Set 3} \\
\hline 35 & \multirow{4}{*}{$\begin{array}{l}\text { Residue of } \\
\text { Expt. No. } 24\end{array}$} & 0.25 & 170 & 75.28 & 2.64 & 0.00 & 14.69 & 2.05 & 94.67 \\
\hline 36 & & 0.5 & 170 & 72.33 & 3.60 & 0.00 & 18.91 & 6.71 & 101.55 \\
\hline 37 & & 1 & 170 & 71.00 & 1.89 & 0.00 & 13.42 & 12.48 & 98.80 \\
\hline 38 & & 2 & 170 & 56.73 & 1.26 & 0.00 & 15.83 & 5.36 & 79.18 \\
\hline
\end{tabular}

Set 1: different $\mathrm{NaOH}$ concentrations at $130^{\circ} \mathrm{C}$;

Set 2: different $\mathrm{NaOH}$ concentrations at $150^{\circ} \mathrm{C}$;

Set 3: different $\mathrm{NaOH}$ concentrations at $170^{\circ} \mathrm{C}$

Residues of $1^{\text {st }}$ step $\mathrm{HNO}_{3}$ treatment, when subjected to a second acidic pretreatment, showed similar trends of component leach outs. Lower acid concentration favors more xylan extraction while higher concentrations cause lignin breakdown. Both temperature and acid concentration affectextraction efficiency, with $150^{\circ} \mathrm{C}$ showing higher extractions than lower temperatures (Table 10 and 11, Expt. Nos. 32-34). However, $170^{\circ} \mathrm{C}$ treatments also show significant cellulose loss, lesser lignin isolation, and substantial sugar degradation deduced from the presence of degradation products (Table 10 and 11, Expt. Nos. 35-38). Sugars are known to spontaneously undergo dehydration in acidic conditions at temperatures above $160^{\circ} \mathrm{C}$, predominantly forming furan derivatives. They further undergo re-polymerization to bind with lignin and contribute to hampered enzymatic hydrolysis, thus resulting in impure sugars and affecting enzyme actions adversely.

Although cellulose obtained after $2^{\text {nd }}$ step $\mathrm{HNO}_{3}$ treatment was obtained in $80 \%$ purity with about $70 \%$ recovery, the residue was found to have diminished enzyme amenability. Hence, it was decided to replace the $2^{\text {nd }}$ step with alkali treatment with a target to solubilize the polymeric lignin residues and xylan; and conserve amorphous cellulose in residue in increased purity. 
Table 11. Effect of $\mathrm{HNO}_{3}$ concentration and temperature on yields of the components in the residue after $2^{\text {nd }}$ step $\mathrm{HNO}_{3}$ pretreatment of rice straw for $30 \mathrm{~min}$ at $7 \% \mathrm{w} / \mathrm{v}$ solid loading at different $\mathrm{NaOH}$ concentrations at $130^{\circ} \mathrm{C}$ in set $1 ; 150^{\circ} \mathrm{C}$ in set 2 ; and $170^{\circ} \mathrm{C}$ in set 3

\begin{tabular}{|c|c|c|c|c|c|c|c|}
\hline \multirow{2}{*}{ Expt. No. } & \multirow{2}{*}{ Biomass } & \multicolumn{5}{|c|}{ Overall yields in residual mass $(\% \mathrm{w} / \mathrm{w})$} & \multirow{2}{*}{$\begin{array}{c}\text { Total weight yield } \\
\text { of residue } \\
(\% \mathrm{w} / \mathrm{w})\end{array}$} \\
\hline & & Glucose & Xylose & Arabinose & Lignin & Ash & \\
\hline \multicolumn{8}{|l|}{ Set 1} \\
\hline 29 & \multirow{3}{*}{ Residue of Expt. No. 24} & 74.68 & 5.02 & 5.18 & 35.60 & 47.82 & 47.37 \\
\hline 30 & & 81.11 & 10.64 & 3.84 & 32.98 & 6.41 & 47.08 \\
\hline 31 & & 83.93 & 12.60 & 4.09 & 19.88 & 30.83 & 47.36 \\
\hline \multicolumn{8}{|l|}{ Set 2} \\
\hline 32 & \multirow{3}{*}{ Residue of Expt. No. 24} & 65.82 & 3.10 & 3.10 & 31.87 & 43.40 & 38.11 \\
\hline 33 & & 68.80 & 8.00 & 4.80 & 27.48 & 0.27 & 36.63 \\
\hline 34 & & 70.69 & 7.21 & 6.41 & 23.61 & 10.60 & 34.96 \\
\hline \multicolumn{8}{|l|}{ Set 3} \\
\hline 35 & \multirow{4}{*}{ Residue of Expt. No. 24} & 77.47 & 4.60 & 0.00 & 39.41 & 8.69 & 41.55 \\
\hline 36 & & 63.89 & 5.37 & 0.00 & 43.55 & 24.43 & 35.67 \\
\hline 37 & & 58.57 & 2.64 & 0.00 & 28.86 & 42.48 & 33.31 \\
\hline 38 & & 51.27 & 1.93 & 0.00 & 37.29 & 20.00 & 36.50 \\
\hline
\end{tabular}

\subsection{Study of effect of $2^{\text {nd }}$ step alkali pretreatment to residue of $1^{\text {st }}$ step acid treatment}

The $2^{\text {nd }}$ step treatment on the residue of the $1^{\text {st }}$ step $\mathrm{HNO}_{3}$ treated biomass was expected to leach out predominantly residual xylan and lignin without affecting cellulose under relatively milder treatment conditions. Hence, $\mathrm{NaOH}$ treatment in the concentration range of $1 \%-2 \%(\mathrm{w} / \mathrm{v})$ was used at $130^{\circ} \mathrm{C}$ for time periods ranging from $15-30 \mathrm{~min}$. The results are presented in Table 12 and 13.

Nitric acid treatment followed by caustic treatment shows a significant drop in xylan content. The $1 \%$ alkali treatment shows greater selectivity for xylan removal than lignin but at an expense of cellulose leach out (Table 12 and 13, Expt. Nos. 39-42). Reduction in temperature cannot extract xylan and lignin selectively (Table 12 and 13, Expt. No. 42). The $2 \% \mathrm{NaOH}$ proves a better choice than $1 \% \mathrm{NaOH}$ with maximum residual lignin and hemicellulose being $\sim 11 \%$ and $\sim 5 \%$ respectively, and cellulose recovery of $\sim 80 \%$. Further improvement in cellulose retention in residue necessities the optimization of step $1 \mathrm{HNO}_{3}$ treatment. Hence, the time of $\mathrm{HNO}_{3}$ treatment was reduced to 15 min and the $2 \% \mathrm{NaOH}$ treatment trials were performed on the residue, in order to reduce cellulose losses (Table 12 and 13, Expt. Nos. 46-49). This helped in a reduction in process time appreciably without any significant changes in xylan and lignin extraction efficiency, and also helped improve residual cellulose retention to up to $\sim 84 \%$ with purity above $90 \%$ (w/w).

The alkali step also helps significantly improve the saccharification efficiency for enzymatic reactions and catalytic conversions. The process also generates a comparatively pure and accessible fraction in terms of cellulose.

Thus, a sequence of fractionation steps was developed to generate cellulose with $\sim 90 \%$ of assay purity and $\sim 85 \%$ of overall cellulose recovery. No other detectable components besides xylose were observed, the residue was given to Dr. Juliet working under another project for enzymatic saccharification to generate monomeric sugars, this work is referred under patent mentioned in reference..$^{39}$ The residue was found to be completely amenable to enzymatic hydrolysis. It was also found to be accessible to catalytic conversions tried in the subsequent studies. This two-step treatment was tried on three representative varieties of LBM, the results are given in Table 14 and 15 below. 
Table 12. Effect of $2^{\text {nd }}$ step alkali treatment at different concentration and time on the fractionation of residue from the first step $\mathrm{HNO}_{3}$ pretreatment of rice straw; $2^{\text {nd }}$ treatment for $30 \mathrm{~min}$ at $7 \% \mathrm{w} / \mathrm{v}$ solid loading in three sets

\begin{tabular}{|c|c|c|c|c|c|c|c|c|c|c|}
\hline \multirow{2}{*}{ Expt. No. } & \multirow{2}{*}{ Biomass } & \multirow{2}{*}{$\begin{array}{l}\text { Reagent } \\
(\% \mathrm{w} / \mathrm{v})\end{array}$} & \multirow{2}{*}{$\begin{array}{l}\text { Temp } \\
\left({ }^{\circ} \mathrm{C}\right)\end{array}$} & \multirow{2}{*}{$\begin{array}{l}\text { Time } \\
(\min )\end{array}$} & \multicolumn{5}{|c|}{ Components present $(\% \mathrm{w} / \mathrm{w})$} & \multirow{2}{*}{$\begin{array}{c}\text { Total } \\
(\% \mathrm{w} / \mathrm{w})\end{array}$} \\
\hline & & & & & Glucose & Xylose & Arabinose & Lignin & Ash & \\
\hline \multicolumn{11}{|l|}{ Set 1} \\
\hline 39 & \multirow{4}{*}{$\begin{array}{l}\text { Residue of } \\
\text { Expt. No. } 24\end{array}$} & $1 \% \mathrm{NaOH}$ & 130 & 5 & 75.51 & 5.34 & 0.00 & 11.38 & 0.40 & 92.64 \\
\hline 40 & & $1 \% \mathrm{NaOH}$ & 130 & 15 & 83.23 & 4.26 & 0.00 & 10.87 & 0.02 & 98.39 \\
\hline 41 & & $1 \% \mathrm{NaOH}$ & 130 & 30 & 85.29 & 4.46 & 0.00 & 7.40 & 2.44 & 99.59 \\
\hline 42 & & $1 \% \mathrm{NaOH}$ & 110 & 30 & 83.51 & 5.39 & 0.00 & 6.43 & 1.20 & 96.53 \\
\hline \multicolumn{11}{|l|}{ Set 2} \\
\hline 43 & & $2 \% \mathrm{NaOH}$ & 130 & 5 & 83.95 & 5.97 & 0.00 & 7.75 & 0.00 & 97.67 \\
\hline 44 & $\begin{array}{l}\text { Residue of } \\
\text { Expt. No. } 24\end{array}$ & $2 \% \mathrm{NaOH}$ & 130 & 15 & 87.92 & 3.21 & 0.00 & 4.65 & 2.14 & 97.92 \\
\hline 45 & & $2 \% \mathrm{NaOH}$ & 130 & 30 & 90.54 & 3.65 & 0.00 & 0.54 & 0.00 & 94.73 \\
\hline \multicolumn{11}{|l|}{ Set 3} \\
\hline 46 & Initial rice straw & $2 \% \mathrm{HNO}_{3}$ & 130 & 15 & 59.28 & 8.87 & 0.21 & 12.88 & 9.52 & 90.76 \\
\hline 47 & & $2 \% \mathrm{NaOH}$ & 130 & 5 & 83.95 & 5.97 & 0.00 & 5.86 & 1.63 & 97.42 \\
\hline 48 & $\begin{array}{l}\text { Residue of } \\
\text { Expt. No. } 46\end{array}$ & $2 \% \mathrm{NaOH}$ & 130 & 15 & 87.85 & 3.25 & 0.00 & 5.96 & 3.53 & 100.60 \\
\hline 49 & & $2 \% \mathrm{NaOH}$ & 130 & 30 & 90.52 & 3.38 & 0.00 & 5.40 & 0.03 & 99.34 \\
\hline
\end{tabular}

Set 1: Utilized residue generated by reaction conditions as mentioned in Expt. No. 24 and treatment with $1 \%$ NaOH at different temperatures and time; Set 2: Utilized residue generated by reaction conditions as mentioned in Expt. No. 24 and treatment with $2 \% \mathrm{NaOH}$ at $130{ }^{\circ} \mathrm{C}$ and different times; Set 3: Utilized residue generated by reaction conditions as mentioned in Expt. No. 46 and treatment with $2 \% \mathrm{NaOH}$ at $130{ }^{\circ} \mathrm{C}$ at different times

Table 13. Effect of $2^{\text {nd }}$ step alkali treatment at different concentration and time on yields of the rice straw components after the first step $\mathrm{HNO}_{3}$ pretreatment; $2^{\text {nd }}$ treatment for $30 \mathrm{~min}$ at $7 \% \mathrm{w} / \mathrm{v}$ solid loading in the same three sets as Table 12

\begin{tabular}{|c|c|c|c|c|c|c|}
\hline \multirow{2}{*}{ Expt. No. } & \multicolumn{5}{|c|}{ Overall yields in residual mass $(\% \mathrm{w} / \mathrm{w})$} & \multirow{2}{*}{$\begin{array}{c}\text { Total weight yield } \\
\text { of residue } \\
(\% \mathrm{w} / \mathrm{w})\end{array}$} \\
\hline & Glucose & Xylose & Arabinose & Lignin & Ash & \\
\hline \multicolumn{7}{|l|}{ Set 1} \\
\hline 39 & 94.79 & 11.34 & 0.00 & 37.25 & 2.05 & 50.69 \\
\hline 40 & 80.96 & 7.01 & 0.00 & 27.56 & 9.57 & 39.28 \\
\hline 41 & 77.00 & 6.80 & 0.00 & 17.42 & 9.09 & 36.46 \\
\hline 42 & 82.88 & 11.46 & 0.00 & 12.87 & 4.89 & 39.94 \\
\hline \multicolumn{7}{|l|}{ Set 2} \\
\hline 43 & 81.81 & 9.84 & 0.00 & 19.69 & 0.00 & 39.35 \\
\hline 44 & 82.23 & 5.08 & 0.00 & 11.33 & 8.25 & 37.77 \\
\hline 45 & 79.48 & 5.42 & 0.00 & 12.38 & 0.00 & 35.45 \\
\hline \multicolumn{7}{|l|}{ Set 3} \\
\hline 46 & 94.66 & 23.95 & 3.73 & 53.62 & 62.69 & 64.48 \\
\hline 47 & 88.95 & 13.55 & 0.00 & 12.53 & 7.11 & 42.65 \\
\hline 48 & 87.91 & 5.51 & 0.00 & 15.55 & 14.59 & 40.41 \\
\hline 49 & 84.25 & 5.32 & 0.00 & 13.10 & 0.13 & 37.58 \\
\hline
\end{tabular}


Table 14. Compositional analysis of residual cellulose after 2-step treatment to fine ground lignocellulosic biomass varieties at optimum parameters

\begin{tabular}{cccccccc}
\hline \multirow{2}{*}{ Expt. No. } & Biomass & \multicolumn{4}{c}{ Component present $(\% \mathrm{w} / \mathrm{w})$} & \multirow{2}{*}{ Total (\% w/w) } \\
\cline { 3 - 6 } & & Glucose & Xylose & Arabinose & Lignin & Ash & \\
\hline 50 & Rice straw & 92.70 & 2.08 & 0.20 & 0.00 & 0.00 & 95.26 \\
51 & Wheat straw & 92.19 & 3.91 & 0.00 & 0.00 & 0.00 & 96.10 \\
52 & Sugarcane bagasse & 83.49 & 3.15 & 0.30 & 7.03 & 0.00 & 93.98 \\
\hline
\end{tabular}

Table 15. Yields of components in residue after 2-step treatment to fine ground lignocellulosic biomass varieties at optimum parameters at $5 \mathrm{~L}$ scale in the same experiments of Table 14

\begin{tabular}{|c|c|c|c|c|c|c|c|}
\hline \multirow{2}{*}{ Expt. No. } & \multirow{2}{*}{ Biomass } & \multicolumn{5}{|c|}{ Yields in residual mass $(\% \mathrm{w} / \mathrm{w})$} & \multirow{2}{*}{$\begin{array}{l}\text { Total weight yield } \\
\text { of residue } \\
(\% \mathrm{w} / \mathrm{w})\end{array}$} \\
\hline & & Glucose & Xylose & Arabinose & Lignin & Ash & \\
\hline 50 & Rice straw & 92.76 & 3.52 & 2.21 & 0.00 & 0.00 & 40.41 \\
\hline 51 & Wheat straw & 89.03 & 8.08 & 0.00 & 0.00 & 0.00 & 38.87 \\
\hline 52 & Sugarcane bagasse & 65.00 & 4.99 & 6.64 & 14.44 & 0.00 & 39.12 \\
\hline
\end{tabular}

\subsection{Characterization of biomass and intermediate residues by XRD and FTIR}

Initial wheat straw and residues generated by treatment at optimum parameters at $5 \mathrm{~L}$ batch scale were screened for XRD and FTIR analysis to study their crystallinity and elucidate structural changes.

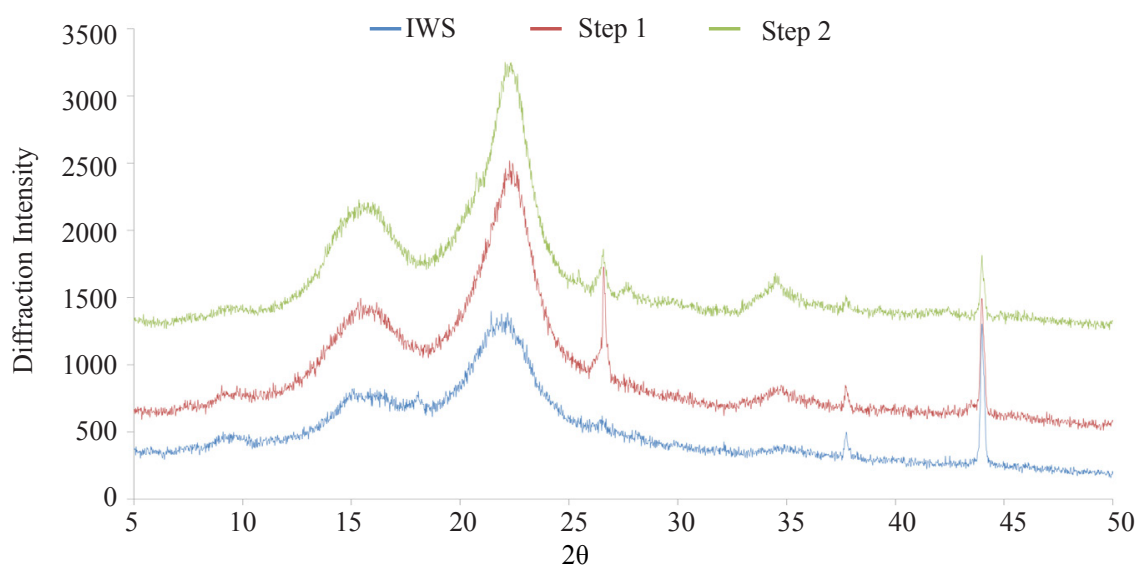

Figure 1. XRD diffractogram for initial biomass and residues of various steps of fractionation

Three major peaks were obtained at the approximate diffraction angle $(2 \theta)$ of $14.8^{\circ}, 22.3^{\circ}$ and $34.7^{\circ}$ which are characteristic peaks of cellulose (I) corresponding to lattice planes (110), (002) and (004). ${ }^{40,41}$ The trough between $2 \theta$ angle of $15.8^{\circ}$ and $22.3^{\circ}$ is roughly observed at $18.5^{\circ}$ and represents the amorphous cellulose. ${ }^{36}$ The peak at $22.3^{\circ}$ represent the maximum diffraction intensity of cellulose including crystalline and amorphous cellulose, according to the Segal equation, deduction of amorphous contribution and division by total intensity depicts the crystallinity of the

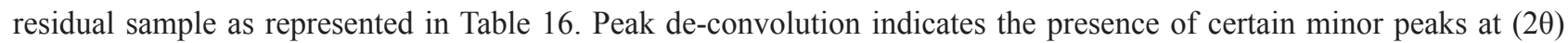
of $19.8^{\circ}, 26.4^{\circ}$ which correspond to (110) of cellulose (II). It can be observed from the de-convoluted peaks in Figure 2(d) that the amorphous peak which is maximum in the initial wheat straw, decreases with the subsequent fractionation 
steps. This may be due to the presence of amorphous lignin and hemicellulose, which on removal in subsequent treatments results in increased crystallinity. Similar results are reported by Zheng et al. ${ }^{42}$ A sharp increase in cellulose (II) characteristic peak (110) at $19.8^{\circ}$ and a proportionate drop in cellulose (I) peak (002) at $22.3^{\circ}$ is seen in the $2^{\text {nd }}$ step $\mathrm{NaOH}$ treatment, which indicates changes in the crystal structure of the cellulose as suggested in the literature. Peak (004) at $35.5^{\circ}$ suggests correlative enhancement in crystalline nature, with subsequent pretreatments. This is the reason for the increased amenability of the residual cellulose to cellulolytic enzyme actions. Proportionate rise is seen in 002 peak indicating the purity of cellulose.

(a) Initial wheat straw

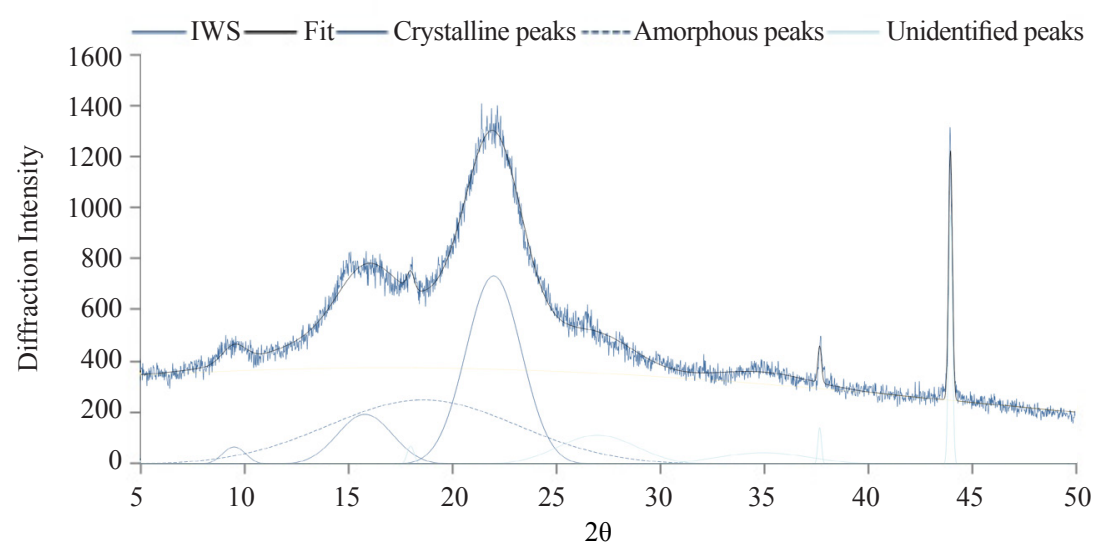

(b) Residue of Step 1



(c) Residue of Step 2

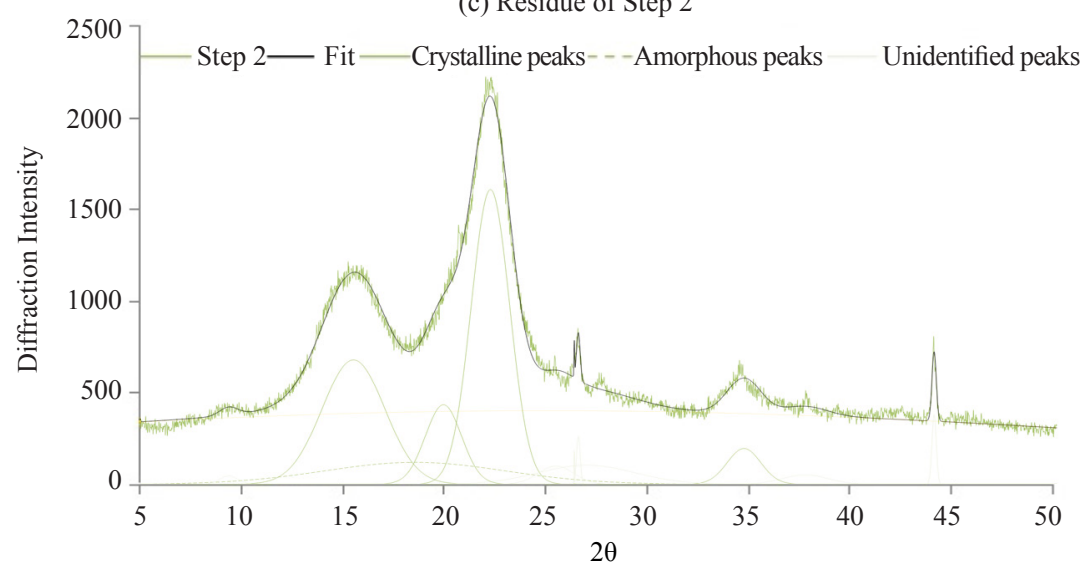


(d) De-convoluted peak estimation

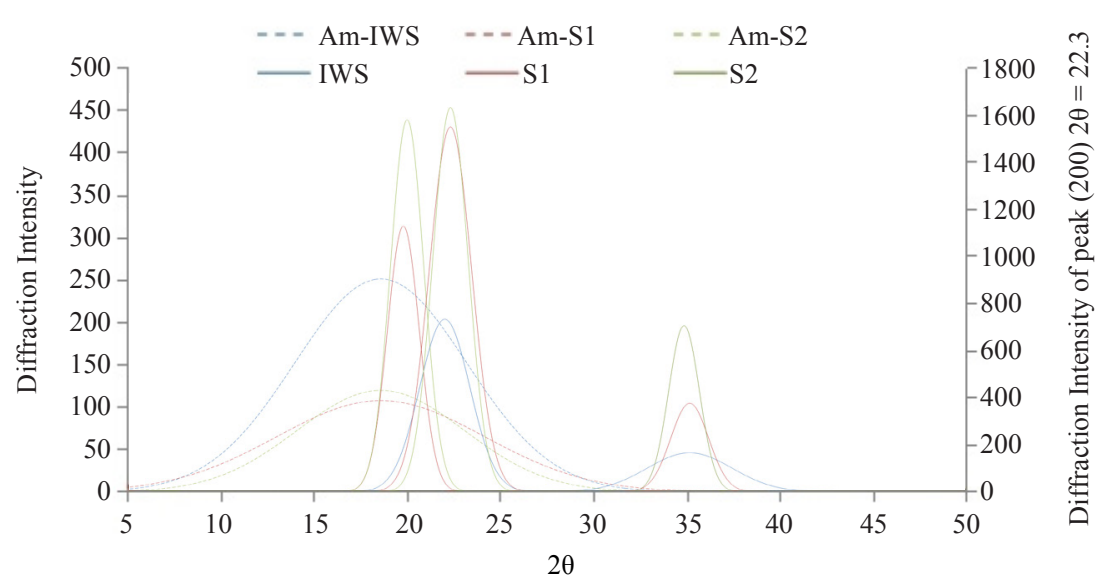

Figure 2. De-convoluted diffractograms for the XRD analysis of initial biomass and residues of various steps of fractionation

Table 16. Evaluation of crystallinity index CrI of initial and residual biomass

\begin{tabular}{cccccc}
\hline Sample & \multicolumn{2}{c}{$2 \theta$} & Intensity & CrI & Data \\
\hline \multirow{2}{*}{ IWS } & $\mathrm{I}_{002}$ & 21.42 & 1398 & $49.64 \%$ & Actual \\
& $\mathrm{I}_{\mathrm{AM}}$ & 18.3 & 704 & & \\
& $\mathrm{I}_{002}$ & 21.46 & 1242.909 & $44.74 \%$ & De-convoluted \\
& $\mathrm{I}_{\mathrm{AM}}$ & 18.34 & 686.8275 & & Actual \\
& $\mathrm{I}_{002}$ & 22.26 & 2264 & $61.22 \%$ & De-convoluted \\
S1 & $\mathrm{I}_{\mathrm{AM}}$ & 18.3 & 878 & & \\
& $\mathrm{I}_{002}$ & 22.3 & 2115.13 & $59.61 \%$ & Actual \\
& $\mathrm{I}_{\mathrm{AM}}$ & 18.34 & 854.3854 & & De-convoluted \\
& $\mathrm{I}_{002}$ & 22.34 & 2246 & $67.14 \%$ & \\
\hline
\end{tabular}

The FTIR spectrum of the initial biomass, fractionated residual cellulose, and recovered lignin displayed characteristic absorption patterns corresponding to the specific functional groups of cellulose and aromatic moieties respectively (Figure 3 ) which can be interpreted with the reported frequency assignment for cellulose (Table 17).

The peaks at 1055,1107 and $1160 \mathrm{~cm}^{-1}$ correspond to asymmetric $\mathrm{C}-\mathrm{O}$ stretching, including pyranose ring stretching of cellulose (I) while 1313, 1363 and 1430 are specific to $\mathrm{CH}_{2}$ wagging, asymmetric $\mathrm{C}-\mathrm{H}$ bending and symmetric C-H bending of cellulose (II) respectively. Sharpening of the above peaks with fractionation indicates removal of lignin and development of more ordered structure. Mild peaks at 1735 and 798 correspond to $\mathrm{C}=\mathrm{O}$ (ketones) of hemicellulose and $\mathrm{C}-\mathrm{H}$ out of plane aromatic bending, as observed for step 1, while their absence along with 1610 and 1592 corresponding to aromatic $\mathrm{CH}_{2}$ and $\mathrm{C}=\mathrm{C}$ stretching from lignin confirms removal of significant quantity of lignin in subsequent steps. Gradual reduction in the peak intensities of lignin as visible in pure lignin and the initial wheat straw chromatogram clearly indicates effect of different fractionation steps. Peaks between 2848 and 2985 correspond to $\mathrm{C}-\mathrm{H}$ stretching of $\mathrm{SP}^{3}$ hybridized methyl and methylene groups. A visible effect is observed on the 2891 and $2868 \mathrm{~cm}^{-1}$ due to structural changes in pyranosic moieties being complexed with $\mathrm{Na}+$ cat ion during caustic 
treatment in step 2. Sharp peaks between 3500 to $3200 \mathrm{~cm}^{-1}$ represents well-ordered crystal structure. The hump near $3000 \mathrm{~cm}^{-1}$ in the spectrogram of lignin may be attributed to aromatic C-H stretching of phenolic moieties of lignin. Table 10 interprets the possible assignment of the observed peaks.

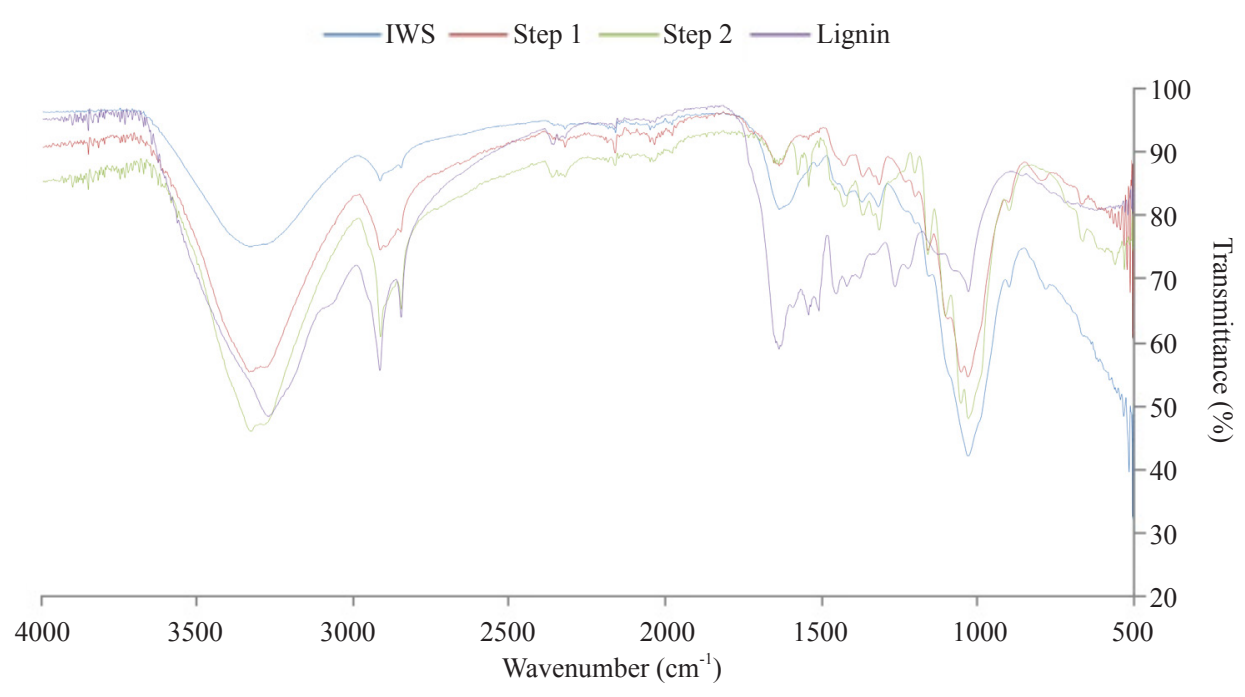

Figure 3. FTIR Spectrograms of the initial biomass, residues of all steps of fractionation, and isolated lignin

Table 17. Peak assignment for the FTIR spectrograms of residues of fractionation

\begin{tabular}{|c|c|}
\hline Wave No. $\left(\mathrm{cm}^{-1}\right)$ & Assignment \\
\hline $3406-3280$ & -O-H stretching, inter-polymer hydrogen bonded \\
\hline \multirow[t]{2}{*}{$2910-2848$} & C-H Stretching, cellulose ${ }^{43}$ \\
\hline & Specific to cellulose \\
\hline 1430 & symmetric bending, cellulose II $^{44}$ \\
\hline 1363 & $\mathrm{C}-\mathrm{H}$ bending, cellulose II $\mathrm{I}^{44-47}$ \\
\hline 1313 & $\mathrm{CH}_{2}$ wagging, cellulose $\mathrm{II}^{44}$ \\
\hline 1160 & $\mathrm{C}-\mathrm{O}$ asymmetric stretching, cellulose $\mathrm{I}^{43}$ \\
\hline 1107 & Asymmetric ring stretching, Cellulose $\mathrm{I}^{44}$ \\
\hline 1735 & $\mathrm{C}=\mathrm{O}$ ketone, hemicellulose residue $\mathrm{e}^{43,48,49}$ \\
\hline 1338 & Overlapping $\mathrm{CH}_{2}$-Aromatic; $\mathrm{C}-\mathrm{O}$ stretching of ether linkage $\mathrm{e}^{43}$ \\
\hline 1369 & $\mathrm{CH}_{3}$ symmetrical angular vibration, overlapping for cellulose and hemicellulose $\mathrm{e}^{50}$ \\
\hline 1055 & C-O-C Pyranose skeletal ring ${ }^{43,48}$ \\
\hline $900-1300$ & $\mathrm{C}-\mathrm{H}$ bending vibration ${ }^{43,51}$ \\
\hline 1641 & -O-H bending of adsorbed water ${ }^{43,53}$ \\
\hline 1610 & $\mathrm{CH} 2$-Aromatic, (Absent-lignin removal) ${ }^{43,54}$ \\
\hline 1592 & $\mathrm{C}=\mathrm{C}$ in plane aromatic vibration ${ }^{40}$ \\
\hline
\end{tabular}

The results of both FTIR and XRD analysis suggest an increase in crystallinity with nitric acid treatment, and the 
change of cellulose (I) to cellulose (II) due to step 2 alkali treatment, which is in good agreement with the amenability of the resultant cellulose to enzymatic saccharification and catalytic conversions. FTIR analysis further confirms a complete removal of hemicellulose and lignin, by a complete absence of peaks corresponding to aromatic hydrocarbons and hemicellulosic ester and ketone linkages.

\section{Conclusions}

A set of two-step physico-chemical pretreatment processes was developed for the fractionation of lignocellulosic biomass varieties, primarily including rice straw, wheat straw, corn cob, corn stover, and sugarcane bagasse to yield a $\sim 90 \%$ pure cellulose in residue with more than $85 \%$ cellulose retention in residue. Major xylan fraction was isolated in hydrolysate that can be utilized for fermentative purposes. The cellulose thus generated was found to show more than $90 \%$ enzymatic saccharification efficiency as determined in another work in our laboratories. ${ }^{39}$

The characteristic analysis of residues by XRD and FTIR also suggest the two-step process being beneficial in terms of fractionation and making residue more accessible for a range of conversions to platform chemicals.

The overall process thus developed utilizes dilute aqueous mineral acid and alkali solutions, under relatively mild conditions to provide added benefits of accelerated solvation and enhanced ionic interactions of resulting aqueous mixture besides resulting in the negligible formation of furan byproducts. Moreover, the working conditions have been so optimized so as to be easily operable at higher batch scale operations or as continuous processes.

\section{Acknowledgements}

This work was financially supported by Department of Biotechnology, Ministry of Science and Technology, and conducted at DBT-ICT Centre for Energy Biosciences, Institute of Chemical Technology, Nathalal Parikh Marg, Matunga (East), Mumbai, Maharashtra-400019. Authors would like to thank India Glycols Ltd. Kashipur, and Privi Specialty Chemicals Limited, Mahad for allowing pilot trials at their facility and making the required resources available.

\section{References}

[1] Himmel, M. E.; Ding, S. Y.; Johnson, D. K.; Adney, W. S.; Nimlos, M. R.; Brady, J. W.; Foust, T. D. Science. 2007, 315, 804-807.

[2] Mosier, N.; Wyman, C.; Dale, B.; Elander, R.; Lee, Y. Y.; Holtzapple, M.; Ladisch, M. Bioresour. Technol. 2005, 96, 673-686.

[3] Karunanithy, C.; Muthukumarappan, K.; Gibbons, W. R. ISRN. Biotechnol. 2013, 2013, 1-13.

[4] Zheng, J.; Rehmann, L. Int. J. Mol. Sci. 2014, 15, 18967-18984.

[5] Karunanithy, C.; Muthukumarappan, K. Appl. Biochem. Biotechnol. 2010, 162, 264-279.

[6] Zakaria, M. R.; Fujimoto, S.; Hirata, S.; Hassan, M. A. Appl. Biochem. Biotechnol. 2014, 173, $1778-1789$.

[7] Gogate, P. R.; Sutkar, V. S.; Pandit, A. B. Chem. Eng. J. 2011, 166, 1066-1082.

[8] Nomanbhay, S. M.; Hussain, R.; Palanisamy, K. J. Sustain. Bioenergy. Syst. 2013, 3, 7-17.

[9] Chen, W.; Yu, H.; Liu, Y.; Chen, P.; Zhang, M.; Hai, Y. Carbohydr. Polym. 2011, 83, 1804-1811.

[10] Chen, W. H.; Tu, Y. J.; Sheen, H. K. Appl. Energy. 2011, 88, 2726-2734.

[11] Montalbo-Lomboy, M.; Johnson, L.; Khanal, S. K.; (Hans) van Leeuwen, J.; Grewell, D. Bioresour. Technol. 2010, $101,351-358$.

[12] Dziekońska-Kubczak, U.; Berłowska, J.; Dziugan, P.; Patelski, P.; Balcerek, M.; Pielech-Przybylska, K.; Robak, K. Energies. 2019, 12, 1715.

[13] Dottori, F. A.; Benson, R. A. C.; Benech, R. O. Separation of reactive cellulose from lignocellulosic biomass with high lignin content. U.S. Patent 8,603.295 B2, December 10, 2013.

[14] Toquero, C.; Bolado, S. Bioresour. Technol. 2014, 157, 68-76.

[15] Cheng, Y. S.; Zheng, Y.; Yu, C. W.; Dooley ,T. M.; Jenkins, B. M.; Vander Gheynst, J. S. Appl. Biochem. 
Biotechnol. 2010, 162, 1768-1784.

[16] Ibrahim, M. M.; El-Zawawy, W. K.; Abdel-Fattah, Y. R.; Soliman, N. A.; Agblevor, F. A. Carbohydr. Polym. 2011, 83, 720-726.

[17] McIntosh, S.; Vancov, T. Bioresour. Technol. 2010, 101, 6718-6727.

[18] Sills, D. L.; Gossett, J. M. Bioresour. Technol. 2011, 102, 1389-1398.

[19] Sharma, S.; Nandal, P.; Arora, A. Waste and Biomass Valorization 2018, 10, 3427-3434.

[20] Kim, S. Int. J. Polym. Sci. 2018, 2018, 1-7.

[21] Tsegaye, B.; Balomajumder, C.; Roy, P. Bull. Natl. Res. Cent. 2019, 43, 136.

[22] Kim, T. H.; Kim, J. S.; Sunwoo, C.; Lee, Y. Y. Bioresour. Technol. 2003, 90, 39-47.

[23] Phitsuwan, P.; Permsriburasuk, C.; Baramee, S.; Teeravivattanakit, T.; Ratanakhanokchai, K. Int. J. Polym. Sci. 2017, 2017, 1-9.

[24] Fan, G.; Wang, M.; Liao, C.; Fang, T.; Li, J.; Zhou, R. Carbohydr. Polym. 2013, 94, 71-76.

[25] Wingerson, R. C. Cellulose production from lignocellulosic biomass. U.S. Patent 6,620,292 B2, September 16, 2003.

[26] Karstens, T. Method for separating lignocellulose-containing biomass. W. O. 2,000,061,858 A1, October 19, 2000.

[27] Jaisamut, K.; Paulová, L.; Patáková, P.; Kotúčová, S.; Rychtera, M. Biomass and Bioenergy 2016, $95,1-7$.

[28] Bajpai, P. Pretreatment of lignocellulosic biomass for biofuel production. Springer Briefs. Mol. Sci. 2016, 17-70.

[29] Mesa, L.; Gonzalez, E.; Cara, C.; Gonzalez, M.; Cartro, E.; Mussatto, S. I. Chem. Eng. J. 2011, 168, $1157-1162$.

[30] Danny, C.; Steven, L.; Pang, Y.; Kam-Huei, W. ICBBE. 2017, 84-90.

[31] Danny, C.; Steven, L.; Pang, Y.; Loong, L.; Chun, L. Energy. Procedia. 2019, 158, 1065-1071.

[32] Panagiotopoulos, I. A.; Chandra, R. P.; Saddler, J. N. Bioresour. Technol. 2013, 130, 570-577.

[33] Tang, S.; Dong, Q.; Fang, Z.; Miao, Z. Bioresour. Technol. 2019, 284, 98-104.

[34] Agbor, V. B.; Cicek, N.; Sparling, R.; Berlin, A.; Levin, D. B. Biotechnol. Adv. 2011, 29, 675-685.

[35] Sluiter, A.; Hames, B.; Ruiz, R.; Scarlata, C.; Sluiter, J.; Templeton, D.; Crocker, D. Natl. Renew. Energy. Lab. Golden, CO. 2008, 1-15.

[36] Segal, L.; Creely, J. J.; Martin, A. E. Jr; Conrad, C. M. Tex. Res. J. 1962, 29, 786-794.

[37] Wadekar, P. C. Recovery and Downstream Chemistry of Lignin. Doctoral Dissertation, Institute of Chemical Technology, Mumbai, India. 2013.

[38] Goring, D. A. I. Trans. of the IIIrd Fund. Res. Symp. Cambridge. 1965; pp 555-568.

[39] Zheng, Q.; Zhou, T.; Wang, Y.; Cao, X.; Wu, S.; Zhao, M.; Wang, H.; Xu, M.; Zheng, B.; Zheng, J.; Guan, X. Sci. Rep. 2018, 8, 1321.

[40] Galiwango, E.; Abdel Rahman, N. S.; Al-Marzouqi, A. H.; Abu-Omar, M. M.; Khaleel, A. A. Heliyon. 2019, 5, e02937.

[41] Yang, Y. P.; Zhang, Y.; Lang, Y. X.; Yu, M. H. IOP. Conf. Ser. Mater. Sci. Eng. 2017, 213, 12039.

[42] Dai, D.; Fan, M. Vib. Spectrosc 2011, 55, 300-306.

[43] Dai, D.; Fan, M. Biotechnol. Biofuels. 2018, 11, 263.

[44] Xu, F.; Yu, J.; Tesso, T.; Dowell, F.; Wang, D. Appl. Energy. 2013, 104, 801-809.

[45] Sun, X. F.; Sun, R. C.; Su, Y.; Sun, J. X. J. Agric. Food. Chem. 2004, 52, 839-847.

[46] Zuluaga, R.; Putaux, J. L.; Restrepo, A.; Mondragon, I.; Gañán, P. Cellulose. 2007, 14, 585-592.

[47] Faix, O. Holzforschung. 1991, 45, 21-28.

[48] Abidi, N.; Cabrales, L.; Haigler, C. H. Carbohydr. Polym. 2014, 100, 9-16.

[49] Johar, N.; Ahmad, I.; Dufresne, A. Ind. Crops. Prod. 2012, 37, 93-99.

[50] Jonoobi, M.; Khazaeian, A.; Tahir, P. M.; Azry, S. S.; Oksman, K. Cellulose. 2011, 18, 1085-1095.

[51] Isogai, A.; Usuda, M.; Kato, T.; Uryu, T.; Atalla, R. Carbohydr. Polym. 2007, 67, 182-189.

[52] Lali, A. M.; Anil, A. O.; Victoria, J. J.; Choudhari, V. G.; Wadekar, P. C.; Patil, M. L.; Patil, P.; Asodekar, B. R.; Mahadik, C. R.; Prakash, I.; Huang, X. Process for production of pure glucose from cellulose. U.S. Patent 10,465,257 B2, November 5, 2016.

[53] Isogai, A.; Usuda, M.; Kato, T.; Uryu, T.; Atalla, R. Macromolecules. 1989, 22, 3168-3172.

[54] Lan, W.; Liu, C.; Yue, F.; Sun, R.; Kennedy, J. Carbohydr. Poly. 2011, 86, 672-677. 